\title{
Augusto y el valle medio del Ebro
}

\author{
Francisco BELTRÁN LLORIS \\ Universidad de Zaragoza \\ fbeltran@unizar.es
}

\section{RESUMEN}

El presente artículo analiza la política de fundaciones y de promoción municipal (tanto latina como romana) que Augusto llevó a cabo en el valle medio del Ebro. Esta política modificó sustancialmente esta región y contribuyó a su recuperación después de un período de guerras civiles, en el que se había visto especialmente afectada.

Palabras clave: Valle medio del Ebro. Colonias romanas. Municipios romanos. Celsa. Osca. Calagurris. Turiaso. Bilbilis. Ilerda. Graccurris. Osicerda. Cascantum. Caesar Augusta.

\section{Augustus and the Middle Ebro Valley}

\begin{abstract}
This paper examines the policy of foundations and promotions to municipal status (Latin and Roman) that Augustus carried out in the middle Ebro Valley. This policy substantially changed this region and contributed to its recovery after a period of civil wars, which had affected it particularly.
\end{abstract}

Key Words: Middle Ebro valley. Roman colonies. Roman municipia. Celsa, Osca, Calagurris, Turiaso, Bilbilis, Ilerda, Graccurris, Osicerda, Cascantum, Caesar Augusta.

Sumario: 1. El valle medio del Ebro a fines de la República. 2. César y la fundación de Celsa. 3. Augusto y el valle medio del Ebro. 4. Los municipios romanos. 5. Los municipios latinos y Caesar Augusta. 6. A modo de conclusión. 
César y Augusto abrieron una nueva fase de la historia provincial romana no sólo por las transformaciones introducidas en la administración, sino sobre todo por sus decididas políticas de emigración dirigida (o colonización) y de concesión colectiva de la ciudadanía (o municipalización). ${ }^{1}$ Estas afectaron en particular a algunas regiones de Occidente, como la Galia Narbonense o la Hispania meridional y oriental, que vieron profundamente alterada la composición política y jurídica de su población. Hispania, en concreto, pasó de tener hacia 50 a.C. siete comunidades privilegiadas, todas colonias latinas, ${ }^{2}$ a contar a la muerte de Augusto con más de cien: 26 colonias romanas, 27 municipios romanos y otros 50 latinos. ${ }^{3}$ Con ello una quinta parte de sus más de quinientas comunidades, incluidas las más prósperas y pobladas, había pasado a formar parte del cuerpo cívico romano o disfrutaba del derecho latino. ${ }^{4}$

En la Tarraconense estas comunidades -43 sin contar las insulares- se concentraban en las regiones orientales, donde en algunas áreas casi la mitad de la población disfrutaba de una condición privilegiada, ${ }^{5}$ pues los territorios centrales y occidentales de la provincia, salvo excepciones, no fueron promocionados hasta época flavia. ${ }^{6}$ De ellas, una docena se ubicaba en el convento cesaraugustano, sobre todo en las proximidades del Ebro: $:^{7}$ dos colonias romanas, Caesar Augusta (Zaragoza) y Celsa (Velilla de Ebro); cinco municipios romanos, Osca (Huesca), Calagurris (Calahorra), Ilerda (Lérida), Turiaso (Tarazona) y Bilbilis (Calatayud); y otros cinco latinos, Cascantum (Cascante), Graccurris (Alfaro), Osicerda (La Puebla de Híjar / Alcañiz), el ilocalizado de Leonica, en algún punto de la provincia de Teruel, y más alejado de los anteriores, ya en la cuenca del Tajo, Ercavica (Cañaveruelas). ${ }^{8}$

1 Al respecto puede consultarse todavía la obra clásica de ViTTINGHOFF 1951.

2 Carteia, Corduba, Valentia, Palma, Pollentia, Carthago Noua y Saguntum; al respecto, véase el estado de la cuestión de F. BeLTRÁn 2011. Amplía esta nómina GarCía 2009.

3 Las cifras se deducen de las noticias de Plinio NH III 7 y 18, y IV 117, de fecha claramente augustea: al respecto, F. BELTRÁN 2007 y EsPinOSA 2013.

4 Sobre la condición política de las ciudades hispanas siguen constituyendo una guía fundamental las monografías de GALSTERER 1971 y WiEgels 1985 así como el trabajo de MARÍn 1988 o la obra colectiva AA. VV. 1989; para la Meseta sur, ALFÖLDY 1987; sobre las fundaciones augusteas, ver ahora ABASCAL 2006.

5 Según las cifras plinianas ( $N H$ III 19-25) entre las 42 comunidades del convento tarraconense había tres colonias, siete municipios romanos y otros siete latinos, lo que supone cerca de un $40 \%$ de comunidades privilegiadas; la proporción baja a c. el $14 \%$ en el cartaginense de cuyas 65 comunidades sólo cinco eran colonias romanas y cuatro municipios latinos; y en el cesaraugustano, con dos colonias, cinco municipios romanos y otros cinco latinos sobre un total de 55 comunidades, se sitúa en torno al $22 \%$.

6 En las regiones occidentales de la Hispania Citerior las únicas ciudades que parecen haber sido promocionadas antes de Vespasiano son Clunia y Termes, Wiegels 1985, 106-108 y 140; sobre Termes ver también Mangas - Martínez CABALlero 2004, y para la concesión flavia del derecho latino, ANDREU 2004.

7 Sobre el período augústeo en el valle medio del Ebro remito a la síntesis de F. BeLtrán (2000, 73-90).

8 Plin. NH III 24: Caesaraugusta colonia immunis (...) recipit populos LV: ex his civium Romanorum Bilbilitanos, Celsenses ex colonia, Calagurritanos qui Nasici cognominantur, Ilerdenses Surdaonum gentis, iuxta quos Sicoris fluvius, Oscenses regionis Suessetaniae, Turiassonenses; Latinorum veterum Cascantenses, Ergavicenses, Gracurritanos, Leonicenses, Osicerdenses. Acerca de la ubicación de las dos últimas comunidades, F. Beltrán 2004. 
En época republicana la cuenca media del Ebro no era sino una serie invertebrada de comarcas culturalmente heterogéneas -ibéricas, célticas, vascónicas- ${ }^{9}$ percibida por Roma como un pasillo de penetración desde sus bases litorales hacia las tierras largamente hostiles del interior; con Augusto, a cambio, se convirtió en un espacio crecientemente estructurado a partir de ese núcleo de ciudades privilegiadas situadas en el centro de la región. ${ }^{10}$ La plasmación más clara de este cambio de tendencia fue la constitución del convento jurídico cesaraugustano: desde luego los conventos no eran distritos administrativos, ni sus comunidades dependían de la sede conventual; sin embargo las reuniones periódicas a las que acudían particulares y delegados de las ciudades para entrevistarse con el gobernador o resolver asuntos judiciales, discutir de materias comunes, celebrar el culto imperial o elegir a sus representantes $-\mathrm{y}$ en particular al flamen conventual- debieron de contribuir paulatinamente a tejer una tupida red de vínculos entre esas comunidades. ${ }^{11}$

En definitiva, el principado de Augusto dio un fuerte impulso a la integración política de las comunidades del Ebro medio y puso las bases para estructurar en torno a una docena de ciudades privilegiadas un extenso territorio antes carente de personalidad. Menos simple resulta precisar cómo se desarrollaron estas medidas a lo largo de los más de sesenta años que median entre las primeras intervenciones de César, en los años cuarenta del I a.C., ${ }^{12}$ y la muerte de Augusto en 14 d.C. A intentar esclarecer los ritmos de este proceso y su contexto histórico regional están dedicadas las siguientes páginas.

\section{El valle medio del Ebro a fines de la República}

A mediados del siglo I a.C. el valle medio del Ebro todavía no se había recuperado de las profundas secuelas ocasionadas por la guerra contra Sertorio. Como es sabido, el general sabino tuvo aquí uno de sus principales puntos de apoyo y fijó en $O s c a$ su última residencia. Ello se tradujo en una elevada incidencia de la guerra en la zona, cuya plasmación más dramática no fueron tanto las destrucciones sufridas por ciudades como Calagurris o Bursao (Borja), como sobre todo el abandono definitivo de otras muchas como el Cabezo de Alcalá (Azaila), La Caridad (Caminreal), La Corona (Fuentes de Ebro), La Cabañeta (El Burgo de Ebro) o Contrebia Belaisca (Cabezo

9 Como es sabido, en la región convergen los tres principales ámbitos culturales y lingüísticos del nordeste peninsular: el ibérico, el celtibérico y el vascónico. Recuérdese que de los diez municipios de la región, tres eran de estirpe celtibérica (Bilbilis, Turiaso, Ercavica), dos ibéricos (Ilerda, Osicerda) y tres vascónicos (Cascantum, Calagurris, Graccurris), a los que hay que sumar la suesetana Osca, en un área de transición entre el ámbito ibérico y el vascónico, y la indeterminada Leonica. Sobre la adscripción étnica y cultural de las comarcas septentrionales aragonesas, F. BELTRÁn 2001.

10 Desarrollo esta perspectiva en F. BELTRÁN 2006.

11 Al respecto, Beltrán - Velaza 2013. Sobre los conventos jurídicos de la provincia, OzCÁRIz 2006 y sobre el cesaraugustano, SANCHO 1981.

12 Existe unanimidad en fechar la concesión de la ciudadanía romana a los gaditanos en 49 a.C.: Cass. Dio, XLI 24.1; Liv., per. 110. 
de las Minas, Botorrita), por mencionar sólo las más conocidas. ${ }^{13}$ Tras la guerra, Pompeyo fundó en tierras vasconas una ciudad peregrina a la que dio su nombre, Pompelo (Pamplona), ${ }^{14}$ a semejanza de lo que hiciera Ti. Sempronio Graco no lejos de allí al establecer Graccurris, también en tierras vasconas, como monimentum operum suorum (179 a.C.). ${ }^{15}$ No concedió, a cambio, condición privilegiada a ninguna comunidad de la región durante su gobierno provincial (55-49 a.C.) a diferencia de lo que hiciera en la costa, si en efecto debe atribuírsele la promoción de Carthago Noua y Saguntum a colonias latinas. ${ }^{16}$ El sucesivo enfrentamiento entre César y los ejércitos pompeyanos no tuvo un gran impacto en la región, pues se dirimió en la, poco cruenta, campaña de Ilerda (49 a.C.). Tras ella, Osca y Iaca (Jaca), junto con otras ciudades más orientales como Tarraco (Tarragona), Auso (Vic) o Ilurgauo -la futura Dertosa (Tortosa)- dieron su apoyo al vencedor, ${ }^{17}$ al igual que Usekerte / Osi(cerda), que utilizó en su emisión bilingüe tipos alusivos a la victoria tomados en parte de monedas emitidas por el propio César en 49-48 a.C. ${ }^{18}$

\section{César y la fundación de Celsa}

En este contexto se inscribe la fundación de la primera ciudad romana de la región, colonia Victrix Iulia Lepida Celsa, ${ }^{19}$ una iniciativa que con el paso del tiempo se reveló desacertada, pues cien años después su núcleo urbano yacía abandonado. Sus epítetos Iulia y Lepida indican que debió de ser planeada por César y fundada por el triunviro Emilio Lépido, gobernador de Hispania Citerior en 48-47 y 44-42 a.C., seguramente durante el segundo mandato y una vez muerto César, quizá en 44 a.C., fecha en la que Lépido se encontraba en Hispania y se hizo acreedor al triunfo por conseguir la retirada de Sexto Pompeyo. ${ }^{20}$ Así, el epíteto Victrix, típicamente cesa-

13 Al respecto M. BeLtrán 2002 y las observaciones de BARRANDON 2011, 231-240; además el catálogo de ciudades de AsEnSIO 1995.

14 Sobre la fundación de Pompelo ver ahora PinA 2011.

15 Liv., per. 41: Tib. Sempronius Gracchus procos. Celtiberos victos in deditionem accepit, monimentumque operum suorum Gracchurim, oppidum in Hispania, constituit. Sobre Graccurris, HeRNÁNDEZ 2011.

16 Sobre la política de Pompeyo en la región véase la síntesis de BARRANDON 2011, 240-246 y, en general, la monografía de Amela 2002. Sobre la condición de colonia latina de Cartagena y Sagunto, véase, por un lado, ABASCAL 2002 y los interesantes epígrafes dados a conocer por RAMALLO - MuRCIA 2010 y, por otro, RIPOLLÉS -VELAZA 2002.

17 Caes., BC I 60.1-2: Interim Oscenses et Calagurritani, qui erant Oscensibus contributi, mittunt ad eum legatos seseque imperata facturos pollicentur. Hos Tarraconenses et Iacetani et Ausetani et paucis post diebus Illurgavonenses, qui flumen Hiberum attingunt, insequuntur.

$18 R R C$ 443. Las monedas osicerdenses muestran una Victoria portando una láurea y un elefante pisoteando una serpiente o carnyx: DCPH 399. Sobre la poco fundamentada posibilidad de explicar estos tipos como consecuencia de un asentamiento de galos en la región, derivado de la inadecuada interpretación del pasaje Caes., BC I 51.1-6, véase F. Beltrán 2006, 195-196.

19 Sobre la ciudad véanse las síntesis de M. BELTRÁn 1983; 1985; 1991.

20 Cass. Dio, XLV 10. Al respecto, Galve 1974, 45; Amela 2001; 2002a; Barrandon 2011, 251-252. Los argumentos numismáticos para datar la fundación en 44 a.C. en M. BELTRÁN ET ALII 1984, 11-19 y un resumen de las diferentes posturas en RPC 110-113. 
riano, podría hacer referencia simultáneamente a los triunfos de César en 45 a.C. ${ }^{21}$ y de Lépido en 43 a.C., ambos sobre los pompeyanos. ${ }^{22}$ La colonia se fundó en el territorio de Kelse, ciudad ibérica de la que tomó su nombre, ${ }^{23}$ seguramente desde su creación, ${ }^{24}$ para la que el establecimiento de la colonia debió de ser un hecho negativo, pues llevaría aparejadas la confiscación de tierras, la instalación de nuevos habitantes y probablemente la exclusión del nuevo cuerpo cívico de sus antiguos pobladores o de una parte de ellos. Por ello cabe la posibilidad, varias veces apuntada, de que Kelse se hubiera alineado con los pompeyanos y fuera por ello así castigada. ${ }^{25}$ No hay noticias explícitas sobre la procedencia de los colonos, quizá veteranos licenciados, pero también ciudadanos romanos procedentes de ciudades vecinas con una marcada presencia itálica como La Cabañeta, destruida en época sertoriana, ${ }^{26} \mathrm{o}$ emigrantes como los atestiguados en torno a Ilerda en 49 a.C. ${ }^{27}$

La ciudad no fue concebida para vertebrar el territorio del Ebro medio -tarea para la que ocupaba una posición muy excéntrica-, sino como un puesto avanzado en el interior, en buena posición para controlar las comunicaciones terrestres y fluviales con el litoral y, en concreto, con otras dos fundaciones cesarianas, la colonia Tarraco, segura, y el municipio Dertosa, probable: ${ }^{28}$ con ésta unida por el río, y con la otra por el ramal que en Ilerda se separaba de la vía Tarraco - Oiasso ${ }^{29}$ y podía cruzar

21 Reflejado también en el epíteto Triumphalis de colonia Tarraco, ALFöLDY 2000.

22 Naturalmente en los acta triumphalia figuran ambos triunfos como ex Hispania. En la acuñación fundacional el anverso exhibe precisamente la cabeza de Victoria con palma (RPC 261).

23 De Kelse se conocen series monetales en bronce y plata (DCPH 235-237). Ptolomeo, II 6.67 la sitúa entre los ilergetes. Su núcleo urbano todavía no ha sido localizado, pero la hipótesis de que deba identificarse con el yacimiento del Cabezo de Alcalá de Azaila, de la que se hace eco, por ejemplo, BARRANDON 2011, 47, no parece suficientemente probada: véase al respecto M. BELTRÁN 2013, 365-366.

24 En las leyendas monetales el nombre de la ciudad aparece como colonia Victrix Iulia Lepida hasta 36 a.C., año de la caída en desgracia de Lépido, y a partir de entonces como colonia Iulia Victrix Celsa. De este hecho tiende a deducirse que la ciudad "cambió" de nombre, es decir que primero se llamaba Lepida y luego Celsa, pero en la práctica lo único que debió ocurrir es que se suprimió del nombre el epíteto Lepida. Que una ciudad no exhiba su nombre completo en las monedas o en las inscripciones es un hecho habitual: Hispalis acuña como Colonia Romula (RPC 73-76), Corduba como Colonia Patricia (RPC 127-131) y Vrso aparece en su lex colonial como Genetiua Iulia (CIL II ${ }^{2} / 5,1022$ = CIL II, 5439); pero cf. Plin. NH III 10: Corduba colonia Patricia cognomine; III 11: Hispal colonia cognomine Romulensis; III 12: Vrso quae Genetiva Vrbanorum.

25 No parece que esta toma de postura pueda deducirse simplemente de la acuñación de moneda bilingüe por Kelse, pues por la misma época hizo lo propio Usekerte / Osicerda con tipos claramente cesarianos. Al respecto, M. Beltrán ET ALII 1984, 12-13. Tampoco resulta evidente que este hecho deba deducirse de la presencia en emisiones de época augustea de tres magistrados con el nomen Pompeius (RPC 269, 276, 278).

26 Mínguez - Díaz 2011.

27 BC I 51.1-6, al respecto F. BELTRÁN 2006, 195-196.

28 En el caso de Tarraco, la promoción cesariana estaría confirmada por una dedicatoria de la colonia a Domicio Calvino, analizada por ALFöLDY 2000 (CIL II, 4134 = CIL II²/14, 977); así lo aceptan, por ejemplo, Ruiz de ARbulo 2002 y ARRAÝ́s 2005. Respecto de la promoción municipal de Hibera Iulia Ilercauonia Dertosa no hay argumentos definitivos: la fecha cesariana, sostenida de antiguo, se apoya en el epíteto Iulia, reforzado quizá por su temprana toma de postura a favor de César tras la batalla de Ilerda (Caes., BC I 60.2); al respecto GALSTERER 1971, 31 y WIEGELS 1985, 110-111 con la bibliografía anterior. Las primeras emisiones del municipio son, sin embargo, tardías, pues parecen datar de fines del principado de Augusto, RPC 101.

29 La vía Tarraco - Ilerda - Osca - Pompelo - Oiasso está documentada por Strab., III 4.10. Sobre los miliarios de Q. Fabio Labeón procedentes de este ramal, Díaz 2008, C6 y C7; no parece, a cambio, que afecte a Celsa el hito terminal comúnmente conocido como el trifinium de Fuentes de Ebro, cuya datación es probablemente anterior a la fundación de la colonia, F. Beltrán 2000a. 
el Ebro gracias al puente construido en las inmediaciones de la colonia. ${ }^{30} \mathrm{La}$ ciudad, sin embargo, no prosperó y en los años 60 d.C., un siglo después de la fundación, su centro urbano fue abandonado, raro fenómeno que no puede explicarse simplemente como consecuencia de la fundación de Caesar Augusta, aunque sin duda la presencia de una vecina tan poderosa hubo de afectarle. ${ }^{31}$

\section{Augusto y el valle medio del Ebro}

A partir del año 42 a.C. Hispania, como el resto de Occidente, quedó bajo el control del joven César, el futuro Augusto, que sin embargo no dirigió personalmente las provincias hispanas, sino que designó como gobernadores a hombres de su confianza. Uno de ellos, Gneo Domicio Calvino (39-37 a.C.), parece haber operado desde Osca en la campaña contra los cerretanos que le valió el triunfo (36 a.C.), ${ }^{32}$ a juzgar por la emisión de denarios con la leyenda $O S C A .{ }^{33}$ Sin embargo, más tarde, Augusto sí visitó Hispania: una vez durante las guerras cántabras, hacia 26-24 a.C., y otra diez años más tarde, hacia 15-13 a.C. ${ }^{34}$ Obviamente, la fundación de una colonia o la promoción municipal de una comunidad no requería la presencia personal del príncipe. Ahora bien en el caso de un programa de intervenciones tan ambicioso como el que experimentó la Hispania meridional y oriental durante este período -recuérdese: 26 colonias romanas, 27 municipios romanos y otros 50 latinos, buena parte de ellos augusteos- resulta razonable suponer que muchas de estas transformaciones se produjeran durante las estancias del príncipe en la península Ibérica, sin descartar la posibilidad de que pudiera incluso asistir personalmente a alguna de las ceremonias de fundación. Augusto entró en contacto con el valle medio del Ebro con seguridad en 26 a.C., pues hubo de atravesarlo dos veces en su camino desde Tarraco hacia el frente cántabro y a su regreso, cuando tras enfermar volvió a la capital provincial, quizá tras una cura de aguas en un lugar que ha sido diferentemente ubicado y que para algunos podría ser Turiaso. ${ }^{35}$ Por, el contrario se ignora cuáles fueron sus mo-

\footnotetext{
30 Strb., III 4.10. Probablemente era el único existente hasta la desembocadura del río.

31 M. Beltrán 1983, 54 y 1991, 25-27.

32 Al respecto, Fatás 2000, Rivero 2002 y Amela 2011.

33 RRC 532 que copia en su anverso el de las monedas de Bolskan y en el reverso el de los denarios de César (RRC 443) en los que se inspiraron también las antes comentadas emisiones de Osicerda.

34 Kienast 1990, 63: Augusto abandonó Roma en mayo / junio del 27 a.C., permaneció en las Galias hasta fines de año y celebró en Tarraco sus consulados octavo (26 a.C.) y noveno (25 a.C.); antes del 13 de junio de 24 a.C. se encontraba de regreso en Roma. En lo que respecta al segundo viaje, el príncipe salió de Roma a comienzos del verano del 16 a.C. y permaneció en las Galias al menos hasta febrero del año 15 (a juzgar por el edicto de Bembibre, $A E$ 1999, $915=2009,583$ ); el 4 de julio del año 13 a.C. estaba ya en Roma.

35 La estancia en un balneario la registra Crinágoras (Anth. Pal. 9, 419) y las principales referencias sobre la enfermedad de Augusto las suministra Suetonio (Aug. 59 y 81), según quien el príncipe se repuso de una afección hepática gracias a la aplicación de fomentos fríos prescrita por el médico Antonio Musa; en Aug. 82 señala también que cuando el príncipe debía tomar baños de mar o las aguas en el balneario de Albula se limitaba a sumergir alternativamente en el agua pies y manos sentado en un taburete de madera (ligneum solium), al que denominaba con un término hispano (Hispanico verbo), seguramente celtibérico, dureta, sobre éste, DE Hoz 2003, 525 que lo vincula directamente con su estancia en el norte de Hispania con motivo de las guerras cántabras. La identificación del lugar donde Augusto se repuso con Turiaso en M. BELTRán 2004, 261-277.
} 
vimientos en 15-13 a.C., más allá de las referencias a la fundación de numerosas colonias en Galia e Hispania ${ }^{36}$ al gasto de grandes sumas y a la concesión generosa de la ciudadanía, ${ }^{37}$ noticias que inducen a pensar que una buena parte de las ciudades privilegiadas por Augusto lo fueron en este momento.

La promoción municipal de una ciudad debía de estar precedida por una solicitud formal ${ }^{38} \mathrm{y}$, para tener éxito, exigiría cuando menos que la comunidad estuviera familiarizada con las formas de vida romanas, hubiera prestado servicios relevantes a Roma, pudiera influir en quien había de tomar la decisión -o en su entorno-y contara con elites capaces de gestionar la ciudad mediante instituciones de corte romano. ${ }^{39}$

No disponemos apenas de información para determinar hasta qué punto cumplían estas condiciones las ciudades del valle medio del Ebro privilegiadas por Augusto ni para establecer con exactitud la cronología de estas promociones, si bien diversos indicios arqueológicos, onomásticos y numismáticos parecen sugerir que se produjo primero la promoción de varios o todos los municipios romanos, en torno a 27 a.C., y, más tarde, la creación de Caesar Augusta, hacia 15/14 a.C., así como de los municipios latinos.

\section{Los municipios romanos}

La datación temprana de la promoción municipal de Osca, Calagurris y Turiaso se fundamenta en el busto anónimo del príncipe de sus primeras acuñaciones, inspirado al parecer en emisiones oficiales de los últimos años ' 30 o primeros '20 y en cualquier caso anteriores a 27 a.C. ${ }^{40}$ Son indicios inseguros que no excluyen una fecha algo posterior, pero que, al menos en las dos primeras ciudades, cuentan con apoyos adicionales y circunstancias favorables para la promoción en este momento.

36 Cass. Dio, LIV 23.7.

37 Cass. Dio, LIV 25.1.

38 Como se señala explícitamente en la inscripción de época de Claudio $A E 1916,43$ relativa a la promoción de Volubilis: M(arco) Val(erio) Bostaris / f(ilio) Gal(eria) Severo, / aed(ili), sufeti, IIvir(o), / flamini primo / in municipio suo, / praef(ecto) auxilior(um) adversus Aedemo/nem oppressum bello, / huic ordo municipii Volub(ilitanorum) ob me/rita erga rem pub(licam) et legatio/nem bene gestam qua ab divo / Claudio civitatem Ro/manam et conubium cum pere/grinis mulieribus immunitatem / annor(um) X incolas(!) bona civium bel/lo interfectorum quorum here/des non extabant suis impetra/vit. / Fabia Bira Izeltae f(ilia) uxor indulge/ntissimo viro honore usa impensam / remisit / et d(e) s(ua) p(ecunia) d(edit) d(e)dic(avit).

39 Gades es un buen ejemplo. Aunque Casio Dión, XLI 24.2 explica que César concedió la ciudadanía romana a la ciudad en agradecimiento del sueño premonitorio de su ascenso al poder tenido en ella durante su cuestura, la ciudad había prestado servicios a Roma desde 206 a.C., disfrutaba de un foedus y contaba con una riquísima elite (Strb., III 5.3), que incluía varios ciudadanos romanos, entre los que destacaba Cornelio Balbo el Mayor, estrecho colaborador de César que, sin duda, debió influir ante éste para que su patria chica se convirtiera en el primer municipio extraitálico. César pasó en Hispania buena parte del año 49 a.C.

$40 \mathrm{El}$ busto de las primeras emisiones de $O s c a$, en concreto $R P C 281$ (y el cuadrante $R P C 282$ con la posible leyenda $M u($ nicipium) - Osca) dependería de RIC 250a, 267, acuñadas hacia 29-27 a.C. o un poco antes; $R P C$ p. 114 con la bibliografía anterior. En el caso de Turiaso, $R P C 402$, que reproduce una estatua ecuestre del joven César, se inspiraría en los áureos $R I C$ 262, datados hacia 32-29 a.C.: RPC p. 130 con la bibliografía anterior; en detalle, M. BELTRÁN 2004, 261-277. En cuanto a Calagurris sus primeras emisiones parecen seguir modelos acuñados hacia 32-27 a.C.: $R P C$ p. 135 con la bibliografía anterior. 
Municipium Urbs Victrix Osca ${ }^{41}$ exhibe dos epítetos muy característicos de fundaciones cesarianas -como Celsa, Tarraco, Carthago Nova, Gades-o, en cualquier caso, anteriores a 27 a.C. ${ }^{42}$ que hacen verosímil una promoción hacia el 30 a.C. Además, la ciudad, antigua capital sertoriana, ${ }^{43}$ estaba familiarizada con las formas de vida romanas ${ }^{44}$ había tomado partido por César ya en 49 a.C. ${ }^{45}$ y acababa de albergar al poderoso Domicio Calvino (cos. 53 y 40), aliado político del futuro Augusto, circunstancias todas ellas que pudieron favorecer su temprana promoción.

Calagurris Iulia Nassica ${ }^{46}$ otra ciudad sertoriana, ${ }^{47}$ exhibe el epíteto Iulia que induce a pensar en un momento temprano, pues tradicionalmente se asocia a fundaciones previas a 27 a.C., como Celsa o Tarraco, aunque esté comprobado también en otras posteriores. La ciudad disponía además de vínculos con César y con Augusto, ${ }^{48}$ pues de ella era oriunda la guardia personal que, heredada seguramente de su padre adoptivo, ${ }^{49}$ protegió al príncipe desde 44 a.C. hasta la batalla de Accio (31 a.C.), ${ }^{50}$ momento en el que fue licenciada y seguramente galardonada con la ciudadanía romana.

Menos elementos de juicio ofrece municipium Turiaso, cuyos epítetos -si los tenía- ignoramos y de la que no puede señalarse ningún vínculo previo con Augusto o con personajes prominentes, salvo su hipotética estancia en la ciudad para tomar las aguas y reponerse de la enfermedad que le afectó durante la campaña cántabra del año 26 a.C. ${ }^{51}$ Lo que está fuera de duda es la enorme devoción que la ciudad le profesaba y que ilustran tanto el retrato palimpsesto de carneola sobre un busto de Domiciano ${ }^{52}$ como las emisiones de época augustea y tiberiana. ${ }^{53}$ De ser histórica la

41 Los epítetos aparecen en las leyendas monetales desde las primeras emisiones: VRB. VICT. OSCA (RPC 281).

42 Victrix lo exhiben en Hispania Osca y Celsa, ambas fundadas en los años 40 a.C. y en otras provincias, Philippi, establecida tras la batalla homónima del 42 a.C., y Thuburbo Minus, en fecha indeterminada pero anterior probablemente a 27 a.C. (VITTINGHOFF 1951, 111), al respecto GALSTERER-KRÖLL 1972, 96 nota 267 y núms. 52, 178, 180, 191, 254 y 398; se excluyen aquellos casos en los que el epíteto deriva del nombre de una legión como en Camulodunum. En cuanto a Urbs aparece entre los epítetos de Tarraco, Carthago Nova y Gades, todas cesarianas, Salacia que probablemente lo es también, y fuera de Hispania en la narbonense Baeterrae, establecida en los años 36-35 a.C. (GALSTERER-KRöLl 1972, 103, 160, 178, 194, 191 y 254.

43 Plut., Sert. 14.

44 De Huesca procede un par de epígrafes latinos de época republicana (DíAz 2008, C108 y C109, con la bibliografía anterior); sobre los restos materiales, ASENSIO 1995, 256-257 y 2003.

45 Caes., BC I 60.1.

46 Así en las primeras monedas (RPC 431-432); el epíteto Nassica (con una sola $s$ en Plin., NH III 24), que desparece en las emisiones posteriores a 27 a.C., no ha encontrado hasta ahora una explicación satisfactoria: ESPINOSA 1984, 86-87.

47 Flor., II 10.9.

48 Ver ahora EsPinosa 2012, 76-79.

49 Suet., Caes. 86.1.

50 Suet., Aug. 49.1.

51 M. BELTRÁN 2004.

52 Ver M. Beltrán, en M. Beltrán - PAz 2004, 89-93.

53 Además de la estatua ecuestre de Augusto asociada a la divinidad local Silbis de la primeras emisiones ( $R P C$ 401-402), hay que señalar el posible retrato de Livia ( $R P C$ 403-407), el uso de la corona de roble que remite al muy augusteo tipo ob civis servatos $(R P C 405-416) \mathrm{y}$, finalmente, las últimas emisiones de Tiberio con Augusto entronizado y DIVVS AVGVSTVS (RPC 422-424): M. BeLTRÁn 2004, 261-295. 
estancia de Augusto en 26 a.C., la promoción podría ser inmediatamente posterior a ella.

Menos datos ofrece municipium Ilerda, pues sus escasas monedas no ofrecen indicios cronológicos sólidos a favor de una promoción temprana o posterior a 16 a.C. ${ }^{54}$ Y lo mismo ocurre con municipium Bilbilis Augusta ${ }^{55}$ cuyas primeras emisiones con la inexplicada leyenda BILBILIS - ITALICA podrían inspirarse en las acuñaciones iniciales de Caesar Augusta, ${ }^{56}$ aunque el busto anónimo del príncipe podría indicar también una cronología anterior.

\section{Los municipios latinos y Caesar Augusta}

En lo que respecta a los municipios latinos de Cascantum, Graccurris y Osicerda, el hecho de que acuñen sólo en época de Tiberio y en escasísima cuantía ${ }^{57}$ no prejuzga en absoluto su fecha de promoción: ${ }^{58}$ resulta evidente que a partir de Augusto la amonedación se concentró en las comunidades romanas y por lo tanto estas comunidades latinas ubicadas junto a las prolíficas cecas de Caesar Augusta y de los municipios romanos del valle sólo acuñaron simbólicamente. Diferente es el caso de Ercavica, municipio latino también pero significativamente alejado del valle, que acuñó varias series, tampoco abundantes, entre Augusto y Calígula. ${ }^{59}$ Ninguno de ellos ofrece indicios de una promoción anterior a c. 15 a.C., ${ }^{60}$ pese a que algunas de estas ciudades contaban con un viejo pasado romano, caso de Graccurris, o habían hecho patente su filocesarianismo como Osicerda.

La pieza básica de este conjunto fue sin duda colonia Caesar Augusta, fundada hacia 15/14 a.C. a juzgar por los hallazgos arqueológicos ${ }^{61} \mathrm{y}$ en relación, por lo tanto, con el segundo viaje de Augusto a Hispania. El príncipe la fundó sin duda con el pro-

54 La vieja hipótesis sostenida por GALSTERER 1971, 11, que hacía de Ilerda una colonia latina para justificar la onomástica parcialmente latina de los jinetes ilerdenses de la turma Salluitana (CIL I², 709), en 89 a.C., no resulta muy convincente: WIEGELS 1985, 116. Si las primeras emisiones con IMP. CAESAR DIVI F. (RPC 259) forman una serie independiente podrían datarse antes de 27 a.C. (M. BELTRÁN - F. BELTRÁN 1980, 30), si por el contrario pertenece a la misma serie que $R P C 260$, para la que se ha propuesto como modelo los denarios RIC 353 de 16 a.C., deberían datar de un momento posterior a esta fecha.

55 El epíteto Augusta aparece por primera vez en monedas posteriores a 2 a.C. (RPC 392-400): $M V N$. AVGVSTA BILBILIS. Una síntesis sobre la ciudad en MARTín-BuENo 2000, 93-102.

56 Según $R P C$ p. 127 , con la bibliografía previa, la primera acuñación bilbilitana $R P C 387$ se inspiraría en los áureos de c. 19-18 a.C. atribuidos a Caesar Augusta (RIC 37a) y en las primeras emisiones coloniales (RPC 304-305) de Q. Lutacio y M. Fabio, que no pueden ser anteriores a c. 15/14 a.C.

57 RPC 425-428 (Cascantum), 429-430 (Graccurris) y 468-469 (Osicerda).

$58 R P C$ pp. 133, 134 y 142 supone, sin argumentos adicionales, una municipalización en época de Tiberio.

59 RPC 459-467.

60 Para Ercavica se ha sugerido una fundación hacia 15 a.C. por argumentos numismáticos no definitivos (véase $R P C$ p. 140); también Segobriga, situada muy cerca, parece haber sido promovida no más tarde de 15 a.C. a juzgar por $A E$ 2004, 809 (ABASCAL 2006, 70-72): que esta ciudad no figure en los listados plinianos no debe obedecer a razones cronológicas, pues evidentemente Caesar Augusta, fundada también c. 15/14 a.C., sí consta.

61 M. Beltrán 1983a, 25-28; MostalaC - Pérez 1989, 94-95; Escudero - Galve 2013, 123; M. BelTRÁN - F. BELTRÁN 2012, 146-148. 
pósito de que se convirtiera en el centro vertebrador de la región. Así lo subraya, en el plano simbólico, el hecho excepcional de que Augusto le concediera el privilegio de llevar su mismo nombre, honor del que ninguna otra ciudad disfrutó y del que me he ocupado en otros trabajos. ${ }^{62}$ En el terreno práctico la ciudad fue agraciada con la $\mathrm{im}$ munitas fiscal ${ }^{63} \mathrm{y}$ recibió un territorio verdaderamente inmenso de unos $60 \times 90 \mathrm{~km} .{ }^{64}$ Toda la ribera derecha del Ebro fue dotada de sistemas de riego que abarcaban también los cursos inferiores de la Huerva y el Aguasvivas gracias a las enormes presas de Muel y de Almonacid de la Cuba, levantadas en época augustea y seguramente con financiación imperial. ${ }^{65} \mathrm{La}$ ciudad, cuya potencia económica ponen de manifiesto sus abundantes emisiones monetales, las más numerosas de Hispania, ${ }^{66}$ fue transformada en el principal nudo de comunicaciones de la región. Además de contar con el tráfico fluvial del Ebro, la red viaria, que antes atravesaba el valle medio del Ebro de este a oeste, fue reformada entre 9 y 4 a.C. y adoptó una disposición radial que convergía en la colonia. ${ }^{67}$ Alguna de estas calzadas, como la vía Caesar Augusta-Pompelo, fue realizada por legionarios que intervinieron también en la construcción de los primeros espacios públicos de la colonia como el foro. ${ }^{68}$ Significativamente, en ella fue fijada la sede del convento jurídico al que dio nombre. ${ }^{69}$

Merece ser subrayado que su enorme pertica -tan grande casi como la de Emerita Augusta- absorbió los territorios de diversas ciudades previas (Salduie, Contrebia Belaisca o Alaun), razón que explica -como seguramente también en Emerita-que el nombre de la colonia no incluya un topónimo, pues en realidad no tomaba el relevo de una sola comunidad previa sino de varias. Y también que esos territorios, como he subrayado recientemente, ${ }^{70}$ se encontraban profundamente desestructurados, pues muchos de sus principales asentamientos yacían abandonados desde época sertoriana: los itálicos de La Cabañeta y La Corona, ${ }^{71}$ los ibéricos de Los Castellazos ${ }^{72}$ y Azaila ${ }^{73}$ o los celtibéricos de El Piquete de la Atalaya (Azuara) - ¿Belikio?- ${ }^{74}$ Contrebia Belaisca (Botorrita) ${ }^{75}$ y La Tijera (Urrea de Jalón). ${ }^{76}$ No hay datos concluyentes, a cambio, respecto de la situación en la que se encontraban en el momento de la funda-

62 F. Beltrán 1992; 2014.

63 Plin., NH III 24.

64 F. Beltrán 2009; 2011; 20141 y F. Beltrán - Magallón 2007.

65 F. BeLtráN - Willi 2011, 23-31.

66 RPC 117.

67 F. Beltrán - Magallón 2007; sobre la red viaria, Magallón 1997.

68 F. Beltrán 2007a.

69 Ver nota 11.

70 F. Beltrán 20141.

71 Asensio 1995, 142 ss. y 235 ss.; Ferreruela - Mínguez 2003, 247-262; sobre La Cabañeta y los materiales itálicos, MíNGUEZ - DíAz 2011, 53-88.

72 Asensio 1995, 216 ss.

73 Asensio 1995, 146 ss; entre las últimas contribuciones, M. BeLtrán 1995 y 2013.

74 Asensio 1995, $272 \mathrm{ss}$.

75 AsENSIO 1995, 168 ss; más bien confusa resulta la síntesis arqueológica presentada por MedRANO DíAz 2001, 13-38.

76 AsENSIO 1995, 294 ss. 
ción la vascónica Alavo $^{77}$ y la propia Salduie, ibérica. ${ }^{78} \mathrm{La}$ ciudad, en consecuencia, no sólo estaba llamada a vertebrar la región, sino a regenerar un amplio espacio desestructurado y semiabandonado desde años atrás, circunstancia que sin duda facilitó la adquisición de los terrenos y el asentamiento de los nuevos colonos.

\section{A modo de conclusión}

Augusto concibió por primera vez el valle medio del Ebro como un espacio con personalidad propia y tomó claras medidas para vertebrarlo a partir de un núcleo de ciudades privilegiadas situadas en su centro, superando con ello la perspectiva republicana que había conducido a la fundación de Celsa. Con las no pocas dudas expresadas más arriba, el príncipe parece haber actuado básicamente en dos fases que se corresponden a grandes rasgos con sus dos estancias hispanas.

Las primeras intervenciones de Augusto parecen encaminadas a promocionar a la condición de municipios romanos a algunas de las ciudades más importantes y más estrechamente vinculadas a Roma o a él mismo de la región, situadas, además, en puntos estratégicos tanto desde el punto de vista de las comunicaciones cuanto en lo que respecta a las diferentes áreas culturales: al norte del Ebro, la ibérica Ilerda y la suesetana $O s c a$, ambas sobre la vieja calzada Tarraco - Oiasso y económicamente potentes a juzgar por sus abundantes emisiones republicanas de plata; al sur del río, las celtibéricas Turiaso, también con importantes emisiones de plata, y Bilbilis, cuyo papel hasta comienzos del siglo I a.C. no fue muy relevante, pero que parece haber tomado a partir de entonces el relevo de la antigua Segeda (Mara - Belmonte de Gracián); y en la parte occidental, Calagurris, ciudad vascónica atestiguada desde el siglo II a.C. cuya promoción debió facilitar la influencia de la guardia de César y Augusto.

Estas ciudades, promocionadas en torno a 27 a.C. con seguridad -en el caso de Osca, Calagurris y Turiaso- o probablemente -Ilerda, Bilbilis-, conformaron junto con Celsa una elipse de comunidades privilegiadas, relativamente distantes unas de otras, que dejaba en el centro el territorio de la futura Caesar Augusta, que, como se ha dicho, en esta época todavía no se había recuperado de las destrucciones provocadas en época sertoriana.

Hacia 15/13 a.C., durante su gira occidental y coincidiendo con la reorganización provincial de Hispania, Augusto fundó en el interior de esa elipse la colonia a la que impuso su propio nombre, Caesar Augusta, con los evidentes propósitos, por un lado, de regenerar el amplio territorio que le atribuyó y, por otro, de articular la vasta región que pasó a constituir el convento jurídico de su nombre.

77 ASENSIO 1995, $131 \mathrm{ss}$.

78 AsENSIO 1995, pp. 318 ss; sobre los materiales ibéricos recuperados en el centro de Zaragoza, fundamentalmente entre la plaza de La Seo y la calle Universidad, AGUILERA 1991, 13-15, incluyendo el importante lienzo de muro de $34 \mathrm{~m}$ de longitud localizado en la calle Sepulcro 1-15, que se ha identificado como un tramo del muro de la ciudad ibérica; el espacio mejor conocido corresponde a unas estructuras domésticas de corte itálico, cuyo nivel de abandono (C2) se fecha a mediados del siglo I a.C.: GALVE 1996; FATÁs - BeltráN 1997, 117. 
Finalmente, la creación de los cinco municipios latinos de la región debió de tener lugar también en este momento. Al margen de los argumentos que estas comunidades pudieran aducir para reclamar su promoción municipal, ésta parece haber respondido también a intereses estratégicos a escala regional. Así, por una parte, Leonica y Ercavica contribuían a vertebrar las regiones meridionales, en las que faltaban por completo las ciudades privilegiadas. Y, por otra, la promoción de Osicerda, Cascantum y Graccurris daba continuidad a los espacios políticamente privilegiados a lo largo del Ebro: Calagurris confinaba al este con Graccurris y ésta con Cascantum, vecina a su vez de Turiaso, por el sur, y de Caesar Augusta, por el este, cuyo enorme territorio era limítrofe al otro extremo con el de Celsa y también con el de Osicerda, que, si en efecto abarcaba o tenía su centro por La Puebla de Híjar, limitaría con Celsa en el Ebro y con Caesar Augusta en el Campo de Belchite. En consecuencia desde Calagurris hasta Celsa toda la ribera del Ebro disfrutaba de la condición romana o latina, convirtiéndose así en una de las áreas más integradas políticamente de Occidente. Habrá que aguardar a que futuros trabajos confirmen o desmientan esta reconstrucción.

\section{BibLIOGRAFÍA}

AA.VV. (1989): Aspectos de la colonización y la municipalización de Hispania, Mérida.

ABASCAL, J. M.

(2002): "La fecha de la promoción colonial de Carthago y sus repercusiones edilicias", Mastia 1, 21-44.

(2006): "Los tres viajes de Augusto a Hispania y su relación con la promoción jurídica de ciudades", Iberia 9, 63-78.

Aguilera, I. (1991): "Salduie”, [en] Zaragoza. Prehistoria y Arqueología, Zaragoza, 13-15.

ALFÖLDY, G.

(1987): Römisches Stadtewesen auf der neukastilischen Hochebene. Ein Testfall für die Romanisierung, Heidelberg.

(2000): "Wann wurde Tarraco römische Kolonie?", [en] G. Paci (ed.), Epigraphai. Miscellanea epigraphica in onore di Lidio Gasperini, I, Tivoli, 3-22.

AMELA, L.

(2001): "La colonia Victrix Iulia Lepida", Kalathos 20-21, 239-249.

(2002): Las clientelas de Cneo Pompeyo Magno en Hispania, Barcelona.

(2002a): "Lépido en Hispania", Hispania antiqua 26, 35-58.

(2011): “Cn. Domicio Calvino y los cerretanos", Hispania Antiqua 35, 43-65.

ANDREU, J. (2004): Edictum, Municipium y Lex: Hispania en época flavia (69-96 d. C.), BAR Int. Ser. 1293, Oxford.

Arrayás, I. (2005): “Tarraco, colonia romana”, Habis 36, 159-178.

Asensio, J. Á.

(1995): La ciudad en el mundo prerromano en Aragón, Zaragoza. 
(2003): “El sacellum in antis del 'Círculo Católico' de Huesca (Osca, Hispania Citerior), un ejemplo precoz de arquitectura templaria romana en el valle del Ebro", Salduie 3, 2003, 93-127.

BARRANDon, N. (2011): De la pacification à l'intégration des hispaniques (133-27 a. C.), Bordeaux.

BeLtrán, F.

(1992): “Caesar Augusta, ciudad de Augusto", Caesaraugusta 69, 31-44.

(2000): “El tiempo de Augusto", [en] F. Beltrán et alii (eds.), Roma en la cuenca media del Ebro, Zaragoza, 73-90.

(2000a): "El terminus republicano de Fuentes de Ebro (Zaragoza)", [en] G. Paci (ed.), Epigraphai. Miscellanea epigraphica in onore di Lidio Gasperini, I, Tivoli, 71-82.

(2001): "Hacia un replanteamiento del mapa cultural y étnico del norte de Aragón", [en] F. Villar - M. P. Fernández Álvarez (eds.), Religión, lengua y cultura prerromana de Hispania, Salamanca, 61-81.

(2004): "Sobre la localización de Damania, Leonica, Osicerda y Orosis", Palaeohispanica 4, 67-88.

(2006): "El valle medio del Ebro durante el período republicano: de limes a conuentus", [en] G. Cruz Andreotti - P. Le Roux - P. Moret (eds.), La invención de una geografía de la Península Ibérica. I. La época republicana, Málaga - Madrid, 217-240.

(2006a): "Galos en Hispania", Acta Archaeologica Academiae Scientiarum Hungaricae 57, 183-199.

(2007): "Locorum nuda nomina? La estructura de la descripción pliniana de Hispania", [en] G. Cruz Andreotti - P. Le Roux - P. Moret (eds.), La invención de una geografía de la Península Ibérica. II. La época imperial, Málaga - Madrid, 115-160.

(2007a): "Marcas legionarias de la VI Victrix y la X Gemina en el foro de Caesar Augusta", Veleia 24-25, 1069-1079 (= Homenaje a Ignacio Barandiarán Maestu).

(2009): "Le territoire de Colonia Caesar Augusta (Saragosse) et ses premiers habitants", [en] L. Callegarin - F. Rechin (eds.), Espaces et societés à l'époque romaine: entre Garonne et Èbre. Hommages à Georges Fabre, Pau, 55-67.

(2011): "Les colonies latines d'Hispanie (II siècle av. E.): émigration italique et intégration politique", [en] N. Barrandon - F. Kirbihler (eds.), Les gouverneurs et les provinciaux sous la République romaine, Rennes, 131-144.

(2011a): "El territorium Caesaraugustanum", [en] I. Aguilera y J. L. Ona (eds.), Delimitación comarcal de Zaragoza. (=Territorio 36), Zaragoza, 83-10.

(2014.): "Colonia Caesar Augusta. Reflexiones sobre el nombre romano de Zaragoza", [en] A. Duplá - M. V. Escribano - L. Sancho - M. A. Villacampa (eds.), "Miscelánea de estudios en homenaje a Guillermo Fatás Cabeza", Zaragoza, 129-139.

(e. p. 1): "Colonia Caesar Augusta: el impacto sobre el territorio y las comunidades indígenas", [en] M. D. Dopico - J. Santos - M. Villanueva (eds.), Las ciudades de poder en Hispania. Revista de Historiografia, en prensa.

Beltrán, F. ET ALII (eds.) (2000): Roma en la cuenca media del Ebro, Zaragoza.

BeltrÁn, F. - Beltrán, M. (2012): “Ama lateres! Sobre una pesa de telar cesaraugustana relativa al lanificium", [en] Nulla dies sine littera. La escritura cotidiana en la casa romana. Instrumenta inscripta IV. (=Sylloge Epigraphica Barcinonensis 10), Barcelona, 127-148.

Beltrán, F. - Magallón, M. Á. (2007): “El territorio”, [en] F. Beltrán (ed.), Zaragoza-Colonia Caesar Augusta, Roma, 97-107. 
Beltrán, F. - VelazA, J. (2013): "El límite occidental del convento jurídico cesaraugustano”, [en] J. Andreu (ed.), Entre Vascones y Romanos: sobre las tierras de Navarra en la Antigüedad, 51-71 (= Cuadernos de Arqueología de la Universidad de Navarra 21).

BeltrÁn, F. - Willi, A. (2011): "El regadío en la Hispania romana. Estado de la cuestión”, Cuadernos de Prehistoria y Arqueología de la Universidad de Granada 21, 9-56.

BELTRÁN, M.

(1983): Celsa, la primera colonia romana en el valle medio del Ebro, Zaragoza.

(1983a): Los orígenes de Zaragoza y la época de Augusto. Estado actual de los conocimientos, Zaragoza.

(1985): Celsa, Zaragoza.

(1991): Celsa, Zaragoza.

(1995): Azaila, nuevas aportaciones deducidas de la documentación inédita de Juan Cabré Aguiló.

(2002): "La etapa de Sertorio en el valle medio del Ebro. Bases arqueológicas", Pallas 60, 45-92. (2004): “Augusto y Turiaso", [en] M. Beltrán - J. Paz (eds.), Las aguas sagradas del Municipium Turiaso. Caesaraugusta 76, Zaragoza, 259-295.

(2013): Azaila. Estado de la cuestión en el año 2013 (contiene documentación inédita de Juan Cabré). (=Caesaraugusta 83).

Beltrán, M. - Beltrán, F. (1980): "Numismática hispanorromana de la Tarraconense”, Numisma 162-164, 9-98.

Beltrán, M. et ali (1984): Colonia Victrix Iulia Lepida-Celsa (Velilla de Ebro, Zaragoza). I, Zaragoza.

Beltrán, M. - PAz, J. (eds.) (2004): Las aguas sagradas del Municipium Turiaso. Caesaraugusta 76, Zaragoza.

$D C P H=$ M. P. García-Bellido - C. Blázquez, Diccionario de cecas y pueblos hispánicos, Madrid 2001.

DE Hoz, J. (2003): “Términos indígenas de Hispania en algunos autores greco-latinos de

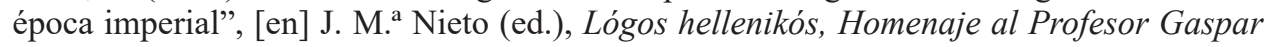
Morocho Gayo, León, 511-532.

DíAz, B. (2008): Epigrafía latina republicana de Hispania, Barcelona.

Escudero, F. - GAlve, M. P. (2013): Las cloacas de Caesaraugusta y elementos de urbanismo y topografía de la ciudad antigua, Zaragoza.

EsPinosa, U. (1984): Calagurris Iulia, Logroño.

Espinosa, U. (2012): "La fundación del municipio Calagurris Iulia Nassica", [en] Historia de Calahorra. Edad Antigua, Calahorra, 76-79.

EspinosA, D. (2013): “La Historia Natural de Plinio el Viejo: un proyecto 'augústeo’ de época flavia”, [en] R. M. Cid - E. García (eds.), Debita verba: estudios en homenaje al profesor Julio Mangas Manjarrés, 1, Oviedo, 671-684.

FAtás, G. (2000): “Gneo Domicio Calvino y la ciudad de Huesca”, [en] F. Beltrán et alii (eds.), Roma en la cuenca media del Ebro, Zaragoza, 37-42.

FAtÁs, G. - Beltrán, M. (1997): Salduie, ciudad ibérica, Zaragoza.

Ferreruela, A. - Mínguez, J. A. (2003): "Dos modelos de implantación urbana romanorrepublicana en el valle medio del Ebro: las ciudades de La Cabañeta y La Corona”, AespA $76,247-262$. 
GALSTERER, H. (1971): Untersuchungen zur römischen Städtewesen auf der Iberischer Halbinsel, Berlin.

GALSTERER-KRöLl, B. (1972): “Untersuchungen zur den Beinamen der Städte des Imperium Romanum”, Epigraphische Studien 9, 44-145.

Galve, M. P.

(1974): Lépido en España. Testimonios, Zaragoza.

(1996): Los antecedentes de Caesaraugusta. Estructuras domésticas de Salduie, Zaragoza.

GARCíA, E. (2009): “Graccuris y los oppida de antiguo Lacio”, [en] J. Andreu (ed.), Los vascones de las fuentes antiguas: en torno a una etnia de la antigüedad peninsular, Barcelona, 215-230.

Hernández, J. A. (2002): "La fundación de Graccurris", [en] A. Ribera - J. L. Jiménez (eds.), Valencia y las primeras ciudades romanas de Hispania, Valencia, 173-182.

KIENAST, D. (1990): Römische Kaisertabelle, Darmstadt.

Magallón, M. Á. (1997): La red viaria romana en Aragón, Zaragoza.

Mangas, J. - Martínez Caballero, S. (2004): "Nuevas inscripciones romanas de Termes (Tiermes, Soria)", Veleia 21, 289-300.

Marín, M. A. (1988): Emigración, colonización y municipalización en la Hispania republicana, Granada.

Martín-Bueno, M. (2000), "Bilbilis", [en] F. Beltrán et alii (eds.), Roma en la cuenca media del Ebro, Zaragoza, 93-102.

Medrano, M. - DíAz, M. A. (2001): "La ciudad celtibérica y romana de Contrebia Belaisca" [en] F. Villar - M. A. Díaz - M. M. Medrano - C. Jordán, El IV bronce de Botorrita (Contrebia Belaisca): arqueología y lingüística, Salamanca.

Mínguez, J. A. - DíAz, B. (2011): “Grafitos sobre cerámica —ibéricos, latinos, griegos y signos - procedentes del yacimiento romanorrepublicanao de La Cabañeta (El Burgo de Ebro, Zaragoza)", AEspA 84, 53-88.

Mostalac, A. - Pérez Casas, J. Á. (1989): "La excavación del foro de Caesaraugusta", [en] La Plaza de La Seo. Investigaciones histórico-arqueológicas, Zaragoza, 81-152.

OzCÁRIz, P. (2006): Los conventos de la Hispania Citerior, Madrid.

PACI, G. (ed.) (2000): Epigraphai. Miscellanea epigraphica in onore di Lidio Gasperini, I, Tivoli.

PInA, F. (2011): “Los vascones, Pompeyo y la fundación de Pompelo", Príncipe de Viana 253, 137-148.

Ramallo, S. F. - Murcia, A. J. (2010): “Aqua et laqus en Carthago Nova. Aportaciones al estudio del aprovisionamiento hídrico en época romana”, ZPE 172, 249-258.

RiberA, A. - JimÉNEZ, J. L. (eds.) (2002): Valencia y las primeras ciudades romanas de Hispania, Valencia.

$R I C=$ C. H. V. Sutherland, Roman Imperial Coinage, London, 1984.

Ripollés, P. P. - VelaZA, J. (2002) :“Saguntum, colonia latina”, ZPE 141, 285-294.

Rivero, M. P. (2002): “La campaña militar de Domicio Calvino en el 39 a.C. y la ubicación de los cerretanos", [en] L. Hernández - L. Sagredo - J. M. Solana (eds.), Actas del I Congreso Internacional de Historia Antigua "La Península Ibérica hace 2000 años", Valladolid, 159-163. 
$R P C=$ A. Burnett - M. Amandry - P. P. Ripollès, Roman Provincial Coinage, I, London Paris 1992.

$R R C=$ M. H. Crawford, Roman Republican Coinage, Cambridge 1974.

Ruiz de Arbulo, J. (2011): “La fundación de la colonia Tarraco y los estandartes de César", [en] J. L. Jiménez - A. Ribera (eds.), Valencia y las primeras ciudades romanas de Hispania, $(=$ Grandes temas arqueológicos 3), Valencia, 137-156.

SANCHO, L. (1981): El convento jurídico caesaraugustano, Zaragoza.

VitTinghoff, F. (1951): Römische Kolonisation und Bürgerrechtspolitik unter Caesar und Augustus, Wiesbaden.

Wiegels, R. (1985): Die Tribusinschriften des römischen Hispanien. Ein Katalog, Berlin. 